\title{
Jessop B.: Putting Civil Society in Its Place: Governance, Metagovernance, and Subjectivity
}

\author{
Policy Press, Bristol, 2020, 276 pp., bibliography, index
}

\author{
Kateryna Pishchikova ${ }^{1}$ (1)
}

Accepted: 29 January 2021 / Published online: 23 February 2021

(c) International Society for Third-Sector Research 2021

Bob Jessop is a living classic in the field of critical governance studies. He is particularly famous for his contribution to state theory and political economy. The title of the book-"Putting civil society in its place"-is a paraphrase of his famous volume from 1990 "Putting the Capitalist State in its Place".

The purpose of the book is to bridge two enormous bodies of literature that have burgeoned over the past several decades: governance and civil society. Both literatures evolved as a response to increasing complexity of state-society relations and reconfigurations of states and markets. Although they often try to address similar challenges, practical and theoretical, the two literatures tend to exist in perfect isolation from each other. They also agree to disagree on the primacy of state, market or society as a key locus of governance. Rather than siding with one of these perspectives, Jessop develops what he calls a "strategic-relational analysis of governance" that keeps these perspectives together, yet each in its place. He sees civil society as a mode of governance with its distinctive coordination logic, principal domains of application and most typical forms of failure. Framed this way, the central concern of the book is how to leverage the power of social networks and solidarity within civil society for governance of the complexity in the contemporary world.

This book is a mouthful, in a positive sense. Books dedicated to civil society often focus on one of the

Book Review Editor: Marc Jegers.

Kateryna Pishchikova

pishchikova@gmail.com

1 eCampus University and Scuola Superiore Sant'Anna, Pisa, Italy following tasks. They discuss civil society theories and the history of ideas about civil society. Alternatively, they explore social and political effects of civil society from a particular theoretical standpoint. They can also share empirical evidence of how civil society actually works under different circumstances. Jessop's book does all three and more. Although each chapter contributes to the whole, it can also be read as a self-standing publication.

The book is structured as follows. The first introductory chapter presents theoretical background to the concept of governance and describes the practice of governance. Chapters 2 and 3 continue with the theoretical discussion of governance in an increasingly complex world, while chapter 4 focuses specifically on the objects, modalities and failures of different types of governance. Chapters 5, 6, and 7 bring together theoretical work from the WISERD (Wales Institute of Social and Economic Research, Data and Methods) project that applies Lockwood's notions of civic stratification and civic repair to civil society research. They also explore the writings of Marx, Gramsci and Foucault in order to place civil society in the context of political economy and politics of governance. Chapters 8 , 9, and 10 present a range of cases: global social policy (GSP) and the discourse of 'good governance' in cities, regional economic governance and the nature of corporatism, and competition as a mode of governance. Finally, the concluding chapter discusses the implications for participatory governance based on an expanded civil society.

Jessop starts by explaining his lack of fondness with the concept of civil society and suggesting to shift the focus to governance. Indeed, the chapters dedicated to governance cover a lot of ground, even if concisely. They explore main theoretical approaches to governance, distinctions between governance and metagovernance, and a dialectic between the governance of complexity and the complexity of 
governance. With respect to civil society, Jessop argues that it exists "at the intersection of networks and solidarity as opposed to markets or command, and its agents have the potential to guide markets and state action" (p. 1). At the same time, he rejects the tripartite classification of market, state and civil society inherited from the Enlightenment in favour of an analysis of hybrid relations of governance. He argues implies that civil society should not be approached as a specific institutional site with its own structured coherence (p. 2).

Jessop further argues that "civil society comprises a heterogeneous set of institutional orders and pluralistic set of agents, many of which are operationally autonomous and resistant to control from outside [...]. It is also the site of identities and interests that are not grounded in any specific institutional order but crosscut them by virtue of their relationship to the experience and 'lifeworld' of whole persons" (p. 1). In other words, "civil society is a rich and confused site of multiple and contestable identities that can be mobilized for both pro- and anti-systemic purposes" (p. 4). Indeed, civil society may serve as a means of self-responsibilization as well as of self-emancipation. While the former is a "top-down strategy to offload governance problems", the latter is a "form of resistance and self-empowerment within wider society" (p. 220).

Self-responsibilization and self-emancipation have been at the forefront of numerous policy approaches and academic debates-local ownership, empowerment, stabilization, resilience-that have only intensified during the COVID-19 pandemic. Does Jessop's work really provides civil society with a new place in the governance debate or does his contribution lie in (re)organizing existing approaches? The book covers so much ground that it is likely to be read as both, depending on the reader's own approach. At any rate, it is a great book for specialists. Although the book is admirable for its scope and rigour, scholars whose primary research focus is on civil society may be left wondering whether the author's attempt at "putting civil society in its place" was not an attempt at putting it out of sight. It is, after all, mostly a book about governance, of which civil society is only a relatively small, if promising, part.

Publisher's Note Springer Nature remains neutral with regard to jurisdictional claims in published maps and institutional affiliations. 